\title{
Microstructure of laser metal deposited duplex stainless steel: Influence of shielding gas and heat treatment
}

\author{
Maria Asuncion Valiente Bermejo ${ }^{1}$ (D) $\cdot$ Karthikeyan Thalavai Pandian $^{1} \cdot$ Björn Axelsson $^{2} \cdot$ Ebrahim Harati $^{1,3}$. \\ Agnieszka Kisielewicz ${ }^{1} \cdot$ Leif Karlsson $^{1}$
}

Received: 31 August 2020 / Accepted: 21 November 2020 / Published online: 5 December 2020

(C) The Author(s) 2020

\begin{abstract}
This research work is the first step in evaluating the feasibility of producing industrial components by using Laser Metal Deposition with duplex stainless steel Wire (LMDw). The influence of $\mathrm{Ar}$ and $\mathrm{N}_{2}$ shielding gases was investigated in terms of nitrogen loss and in the microstructure and austenite content of different deposited geometries. The evolution of the microstructure in the build-up direction of the $\mathrm{Ar}$ and $\mathrm{N}_{2}$-shielded blocks was compared in the heat-treated and as-deposited conditions. The susceptibility for oxygen pick-up in the LMDw deposits was also analyzed, and oxygen was found to be in the range of conventional gas-shielded weldments. Nitrogen loss occurred when Ar-shielding was used; however, the use of $\mathrm{N}_{2}$-shielding prevented nitrogen loss. Austenite content was nearly doubled by using $\mathrm{N}_{2}$-shielding instead of Ar-shielding. The heat treatment resulted in an increase of the austenite content and of the homogeneity in the microstructure regardless of the shielding gas used. The similarity in microstructure and the low spread in the phase balance for the as-deposited geometries is a sign of having achieved a stable and consistent LMDw process in order to proceed with the build-up of more complex geometries closer to industrial full-size components.
\end{abstract}

Keywords Duplex stainless steels · Additive manufacturing · Laser metal deposition · Directed energy deposition · Laser beam additive manufacturing

\section{Introduction}

Additive manufacturing (AM) has the potential to revolutionize the industry worldwide for several reasons: minimal material wastage, short time-to-market, flexibility in the geometry and design of the components produced, and the possibility to improve their functionality, by for example producing functionally graded materials. The European Union, aware of the importance of AM, has been supporting its establishment through research projects funded by the Horizon 2020 Program [1-3].

Recommended for publication by Commission IX - Behaviour of Metals Subjected to Welding

Maria Asuncion Valiente Bermejo

asun.valiente@hv.se

1 Department of Engineering Science, University West, 461 86 Trollhättan, Sweden

2 Alfa Laval Tumba AB, 14780 Tumba, Sweden

3 ITW Welding AB, 43325 Partille, Sweden
However, there are still important technological and scientific challenges ahead in connection to the industrial implementation of the technique, for example, the in-process monitoring and control, the reduction of post-processing steps, the simulation and measurement of thermal gradients and residual stresses, and very importantly and connected to the previous challenges, the control of the resulting microstructure. Because of the difficulty to predict and control the temperature gradients reached in the material during the manufacturing process, there is still no way to control the microstructure that will be produced. Before reaching that stage and to guarantee the safety of the AM components, it is necessary to gain fundamental understanding of each specific additive manufacturing process and of the relationship between the different process parameters and settings and their influence on the resulting microstructure and properties.

Among the several AM processes, the Laser Metal Deposition with wire (LMDw), also known as Laser Directed Energy Deposition with wire (LDEDw) or Laser Beam Additive Manufacturing with wire (LBAMw), is a promising pathway in future industrial production. The reason is that it 
combines the advantages of AM, stated earlier, with the versatility of the laser as the energy source and with the productivity and cost advantages that wire-based techniques possess over the powder-bead based methods [4]. Besides, it is potentially amendable to superior process control.

The above-mentioned advantages and possibilities of LMDw together with the outstanding mechanical and corrosion properties of duplex stainless steels have increased the interest of the industry in the feasibility of producing full-size industrial components in duplex stainless steel using LMDw. From the research conducted in welding, it is well known that when welding duplex stainless steels by using low energy input processes such as laser beam, a highly ferritic microstructure is expected because of rapid cooling and/or the associated nitrogen loss [5, 6]. It is also known that detrimental phases can form due to multiple reheating in multi-pass welding of duplex stainless steel grades [7, 8]. Therefore, the same phenomena are expected to occur when depositing duplex stainless steels by using LMDw, with the particularity that except for the last deposited layer, the rest of layers in the build-up can be considered "heat-affected zones." The main aim of this piece of work is to gain fundamental knowledge of the influence that different shielding gases have on the microstructure and phase-balance of duplex stainless steel asdeposited by LMDw and after having been heat treated.

In connection to AM of duplex stainless steels, there are recent works published related to powder-bed fusion processes and to arc processes as described below. Some research has been conducted with duplex stainless steel powder and selective laser melting (SLM) [9-12], which is an AM technique based on powder-bed fusion. In all cases, the researchers used argon shielding and it was necessary to apply a post-process heat treatment to reach a balanced austenite to ferrite ratio. An important concern was the density of the material achieved, and values of around $90 \%$ in density were reported, meaning that around the $10 \%$ of the deposit were voids related to a partial melting of the powder. Interestingly, it was found that an argon-shielded laser beam process has been used to fabricate duplex stainless-steel microstructures by mixing austenitic and ferritic powders in different percentages. The authors evaluated the residual stress distribution in that functionally graded material [13]. In the last 2 years there has been a boost in publications related to the study of duplex stainless steels deposited when using AM processes that use electric arc as the power source and wire as a feedstock, commonly designated as Wire Arc Additive Manufacturing (WAAM) [14-21].

Within the last year, a couple of studies were published in relation to the physical simulation of the thermal cycles experienced by super-duplex stainless steels during the reheating, using Gleeble [22] and using arc-heattreatment [23]. These could be very helpful tools to simulate the microstructure of the repeatedly reheated material, as that occurs in AM.
However, what has not been possible to find publications about is specifically LMDw of duplex stainless steels, which is the subject of study in this work. Therefore, the way to start developing and investigating has to be grounded in the current knowledge acquired from Laser Beam Welding (LBW) of these alloys. In terms of shielding gases, argon, helium, nitrogen, and argon-helium mixtures are recommended when LBW duplex grades [6]. The argon-shielding in LBW of duplex stainless steel is commonly used [24-27]. However, the literature shows that higher austenite content and better toughness can be achieved when using nitrogen shielding [28]. One author also used a defocused laser beam immediately after LBW (Ar-shielded) but using local nitrogen shielding to obtain a balanced austenite-ferrite resulting microstructure [29]. The above-mentioned results with LBW motivated part of this research work aimed at determining and comparing the influence of argon and nitrogen shielding gas on the microstructure and nitrogen loss when depositing duplex by LMDw.

Another aspect that was specifically investigated in this work was if oxygen pick-up could be a concern in LMDw of duplex stainless steels. It is well-known that oxygen content is detrimental for pitting corrosion resistance due to the formation of oxide inclusions that act as pit initiation sites [30] and for mechanical properties, especially for impact toughness [31] in duplex stainless steel weldments.

\section{Experimental}

In this chapter, the laser metal deposition experiments and the testing and characterization methods are described.

\subsection{LMDw: experiments and settings}

Duplex stainless steel type 2205 (UNS S32205) in 10-mmthick plates was used as the substrate material for the experiments. The filler material was duplex stainless steel type 2209 (EN ISO 14343-A: G $2293 \mathrm{~N} \mathrm{~L}$ ) in 1.2-mm-diameter wire format. Table 1 includes the chemical analysis of the substrate and the wire. Commercially pure argon ( $>99.995 \%)$ and pure nitrogen (>99.999\%) were used as shielding gases.

The power source was a 6-kW Ytterbium-doped fiber laser working in continuous mode. The focal length was $300 \mathrm{~mm}$ and the wavelength was $1070 \mathrm{~nm}$. The depositions were performed with an out-of-focus spot diameter of approximately $3.2 \mathrm{~mm}$ characterized by a Gaussian intensity profile. The main control actions were performed by a programmable logic control (PLC). The elements of the system, such as the wirefeeding system, the deposition tool with the laser optics, and the controller and actuators, were mounted on an industrial robot. Hence, the robot governed the movement of the deposition tool according to a set pattern. A picture of the system setup is shown in Fig. 1. During deposition, an electrical 
Table 1 Chemical analysis (wt\%)

\begin{tabular}{llllllllllll}
\hline Material & $\mathrm{C}$ & $\mathrm{Si}$ & $\mathrm{Mn}$ & $\mathrm{Ni}$ & $\mathrm{Cr}$ & $\mathrm{Mo}$ & $\mathrm{N}$ & $\mathrm{S}$ & $\mathrm{P}$ & $\mathrm{Cu}$ & $\mathrm{Co}$ \\
\hline Plate & 0.016 & 0.32 & 1.77 & 5.50 & 22.77 & 3.07 & 0.177 & $<0.001$ & 0.027 & 0.21 & 0.096 \\
Wire & 0.016 & 0.45 & 1.45 & 8.62 & 23.23 & 3.29 & 0.160 & 0.001 & 0.016 & 0.04 & - \\
\hline
\end{tabular}

current was flowing through the wire and melt pool, creating a hot-wire effect. The level of the voltage and the current was regulated by a set of electrical power supplies. These values were measured on-line and used for process monitoring and control purposes. The control actions were aiming at a specific wire resistance that resulted in a stable metal transfer, good wettability, and a proper dimensional tolerance.

Three types of geometries were produced in this study: single-bead, single-bead-wide and 10-layer-high walls and 10-layer-high and 5-bead-wide blocks resulting in blocks of $140 \mathrm{~mm}$ in length, $20 \mathrm{~mm}$ in width, and $5 \mathrm{~mm}$ in height.

In all cases, samples were deposited using two different shielding gases $\left(\mathrm{Ar}\right.$ and $\left.\mathrm{N}_{2}\right)$ and were investigated in the as- deposited condition. In addition, for the blocks a PWHT was applied (solution annealing at $1100{ }^{\circ} \mathrm{C}$ for $1 \mathrm{~h}$ followed by water quenching). The process parameters used to prepare the samples are listed in Table 2, and Table 3 shows the list of different conditions evaluated in this work.

\subsection{Testing and characterization}

The microstructural characterization was performed by using Olympus BX60M and Zeiss AL10 optical microscopes. Sections were prepared using the general lab equipment for mounting, grinding and polishing to $0.05 \mu \mathrm{m}$. To reveal and contrast austenite from ferrite, the samples were etched just

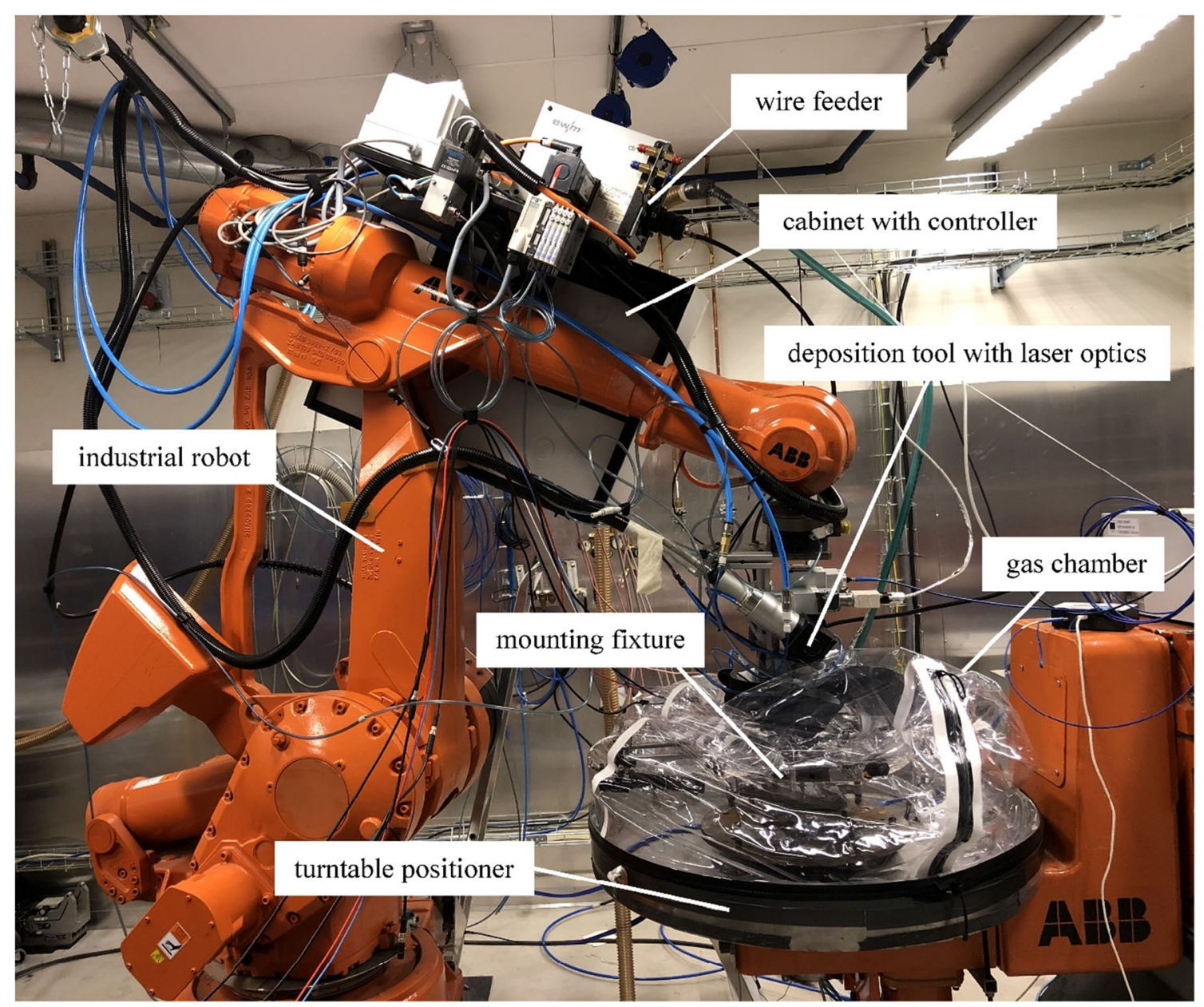

Fig. 1 Laser metal deposition setup: industrial robot with turntable positioner, deposition tool, gas chamber, wire feeding, and control systems 
Table 2 Process parameters used in the depositions

Single bead and 10-layer blocks

10-layer wall

$\begin{array}{lll}\text { Laser power }(\mathrm{kW}) & 3.5 & 3.5 \\ \text { Wire feed rate }(\mathrm{m} / \mathrm{min}) & 2 & 2 \\ \text { Transverse speed }(\mathrm{mm} / \mathrm{s}) & 10 & 10 \\ \text { Hot-wire voltage }(\mathrm{V}) \text {-Average value } & 2.5 & 1.5 \mathrm{~V} \text { in the first layer and } 1 \mathrm{~V} \text { in the subsequent layers } \\ \text { Hot-wire current }(\mathrm{A}) \text {-Average values } & 23-26 & 101 \mathrm{~A} \text { in the first layer and } 68 \mathrm{~A} \text { in the subsequent layers }\end{array}$

immediately after polishing for about $10 \mathrm{~s}$ using a modified Beraha etchant consisting of $33 \% \mathrm{HCl}, 66 \%$ water, and $1 \%$ potassium bisulfite freshly prepared [32]. To reveal possible sigma-phase, the samples were electrolytically etched with $40 \% \mathrm{NaOH}$.

A stitching function at Zeiss AL10 was necessary to take full cross-section images of the built geometries, and Image Pro software was used to measure the austenite content by image analysis.

For image analysis, and based on previous investigations, for each deposited layer, 8-9 images at $\times 50$ magnification were used to get a representative value of austenite content. These 8-9 locations were homogeneously distributed across the layer as shown in Fig. 2 for single-bead, in Fig. 3 for the walls, and in Fig. 4 for the blocks. Note that Fig. 3 corresponds to an 8-layer-trial wall, not to the final 10-layer wall, but the aim of the image is to show the distribution of locations chosen for the austenite measurements.

For the single-bead and 10-layer walls, nitrogen and oxygen contents were determined by combustion analysis using a LECO TC-436 analyzer. One test was performed per sample.

For the 10-layer, 5-bead blocks, nitrogen was measured by optical emission spectroscopy (OES) in a cross-section of the block at seven locations at the bottom layers and at six locations at the top layers of the block (Fig. 5). Both methods, OES and LECO, were calibrated and expected to provide roughly the same accuracy.

The blocks were annealed at $1100{ }^{\circ} \mathrm{C}$ for $1 \mathrm{~h}$ and water quenched afterwards by following industrial practice. This heat treatment temperature was decided based on the literature [33] and on the estimation of sigma-phase formation temperature and nitrogen solubility versus ferrite content calculated

Table 3 Conditions investigated and samples' designation

Ar-shielding $\mathrm{N}_{2}$-shielding Ar-shielding $\mathrm{N}_{2}$-shielding

\begin{tabular}{lllll}
\hline \multicolumn{3}{l}{ As-deposited } & \multicolumn{3}{l}{ Heat-treated } \\
Single-bead & A1 & N1 & - & - \\
10-layer wall & A10 & N10 & - & - \\
10-layer block & B-A-AD & B-N-AD & B-A-HT & B-N-HT \\
\hline
\end{tabular}

by computational thermodynamics (Thermo-Calc $\AA$ software with TCFE8 database) for the chemical composition of the specific 2209 batch used.

\section{Results}

In this chapter, the results of analyzing the oxygen content and the nitrogen content in the deposits are presented, as well as the microstructural inspection including an evaluation of the austenite content in the deposits.

\subsection{Oxygen content}

Table 4 contains the oxygen content measured in the singlebead and the 10-layer walls produced under Ar-shielding and $\mathrm{N}_{2}$-shielding deposited metal. In all the cases, the oxygen values were in between 111 and $160 \mathrm{ppm}$, which are values in the range of the oxygen values that can be found in conventional gas tungsten arc (GTA) weldments [34].

\subsection{Nitrogen content}

Figure 6 shows the nitrogen content measured by combustion technique in the single-bead and the 10-layer walls produced under Ar-shielding and $\mathrm{N}_{2}$-shielding specimens and the nitrogen content measured by OES in the 10-layer, 5-bead blocks which were Ar-shielded and $\mathrm{N}_{2}$-shielded, as-deposited and heat-treated (Fig. 5).

From the results, it is clear that nitrogen loss is a fact in the LMDw specimens when using Ar-shielding, as the deposited material contains less nitrogen than the wire $(0.16 \mathrm{wt} \%)$. It is also clear that the nitrogen loss increases when increasing the number of deposited beads. In the deposition of the single-bead, the relative nitrogen loss was in the range of $14 \%$ and the relative loss of nitrogen in the top of the 10-layer wall was found to be of $26 \%$. In the blocks, the top layers showed a relative reduction in nitrogen content in the range of 4 to $10 \%$. When comparing the nitrogen content in the bottom layers with the nitrogen content in the wire, a $25 \%$ of relative loss in nitrogen was found. 
Fig. 2 Locations where images were taken for austenite measurement in the single-bead specimens: 5 locations in the bottom zone of the bead and 4 locations in the top zone

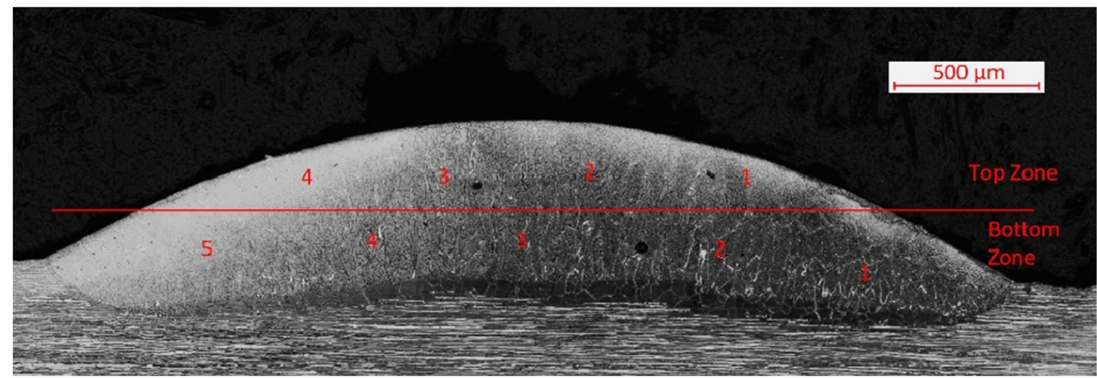

\subsection{Microstructure and austenite content}

Cross-sections of each type of sample were used to inspect the microstructure and to measure the austenite content. Figure 7 shows the austenite values measured for the single-bead and for the 10-layer walls (measurement locations illustrated in Figs. 2 and 3). At first glance it is evident that austenite content is higher when using $\mathrm{N}_{2}$-shielding than when using $\mathrm{Ar}$ shielding. When comparing the austenite content of the layers that were not reheated (i.e., single-bead and layer number 10 in the wall), it seems clear that austenite content is nearly doubled just by using $\mathrm{N}_{2}$-shielding instead of Ar-shielding. As expected, the reheated layers showed higher austenite content than the as-deposited, and the average austenite values showed a low spread within each shielding gas used: from 33 to $39 \%$ in Ar-shielded and from 53 to $67 \%$ in the $\mathrm{N}_{2}$ shielded. Again, the austenite content is nearly doubled when

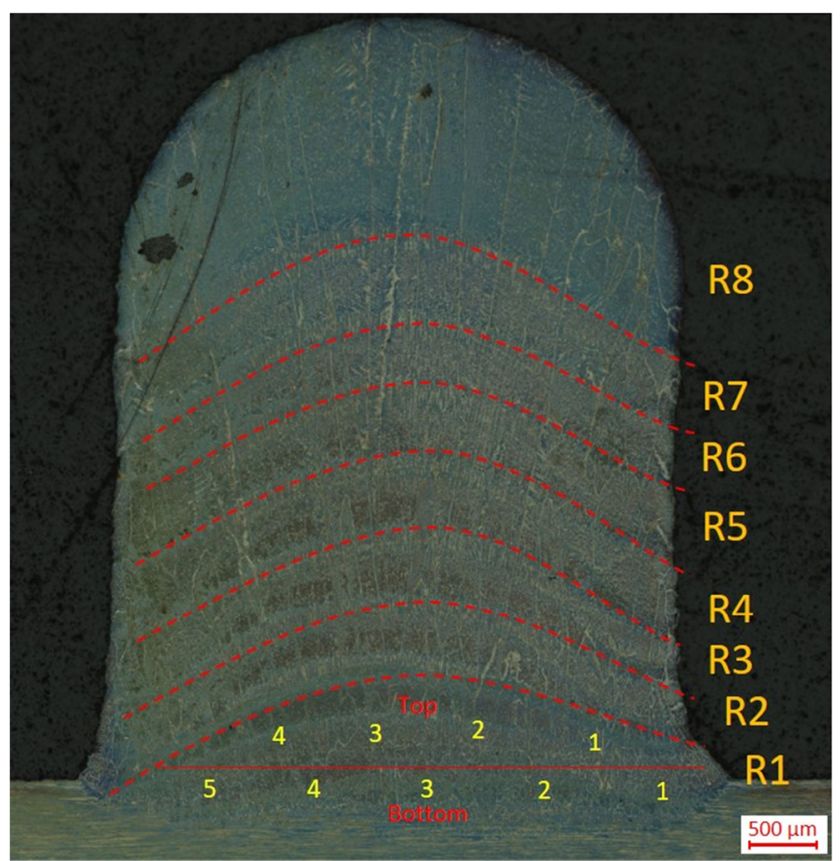

Fig. 3 Locations where images were taken for austenite measurement in the walls: 9 locations in the first layer distributed between top and bottom and bottom. The same approach was followed in the subsequently deposited layers. Note that this is an 8-layer trial wall, not the 10-layer wall investigated in this study comparing the austenite content of the reheated layers shielded with nitrogen.

Figure 8 presents the austenite values measured for the 10layer $\times 5$-bead blocks in the as-deposited and heat-treated conditions (measurement locations illustrated in Fig. 4). Similar to the results presented for the 10-layer wall, the austenite content is higher when using nitrogen as a shielding gas compared with when using argon. The austenite average values measured at each layer in the as-deposited blocks are in the same range as those obtained at each layer of the walls. When looking at the heat-treated blocks, the austenite content increases from $36-41 \%$ to $52-54 \%$ when $\mathrm{Ar}$ was used for shielding. That represents a $38 \%$ relative increase in austenite caused by the heat treatment. When using $\mathrm{N}_{2}$-shielding the austenite content globally increases due to the heat treatment, but considerably less. In some layers, the average value was the same. The maximum difference found was $63 \%$ austenite in the as-deposited condition and $70 \%$ austenite in the heattreated, representing only an $11 \%$ relative increase of austenite caused by the heat treatment. What is important to note is that the values measured in the heat-treated samples had a very low variation, meaning that the standard deviation of the average value in each layer was lower than the standard deviation of the average values when the blocks were as-deposited.

Figures 9, 10, and 11 illustrate the evolution of the microstructure in the different types of samples.

In Fig. 9, the microstructure of the single-bead samples prepared with $\mathrm{Ar}(\mathrm{A} 1)$ and $\mathrm{N}_{2}(\mathrm{~N} 1)$ is presented. As expected, ferrite and nitrides are found in a higher amount in the $\mathrm{Ar}$ shielded single-bead than in the $\mathrm{N}_{2}$-shielded one. Nitrides are illustrated at higher magnification in Fig. 12. In the Arshielded deposit, primary intergranular austenite is formed along the ferritic grains, but it is possible to observe original ferritic grain boundaries without austenite formation. Widmanstätten austenite is scarcely found, and it is possible to find fine intragranular austenite within the ferritic grains. On the other hand, in the nitrogen-shielded sample, the intergranular austenite is found along all the grain boundaries, Widmanstätten austenite is clearly visible, and the intragranular austenite is bigger in size than in the microstructure produced with Ar-shielding.

In Fig. 10, the evolution of the microstructure along a vertical line that crosses the 10 layers is shown for the 10-layer 
Fig. 4 Locations where images were taken for austenite measurement in the blocks: a matrix of 8 locations on the horizontal axis - shown in bluethat was repeated per each one of the 10 layers - shown in purple

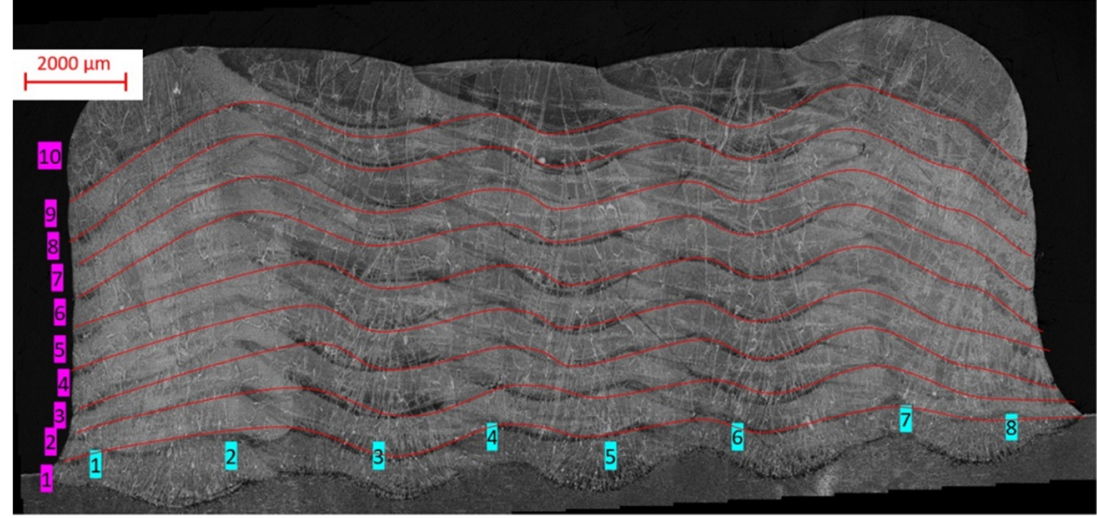

walls shielded with $\operatorname{Ar}$ (A10) and $\mathrm{N}_{2}$ (N10). By looking at the macro sections, epitaxial growth is clearly observed in the fusion boundaries and beads showed a convex profile.

In the Ar-shielded wall, when comparing the non-reheated layer (last layer) with the reheated layers, it is possible to observe the formation of secondary austenite and the growth or coarsening of the primary austenite (intragranular, Widmanstätten, and intergranular). No big differences can be found in the microstructural features within the reheated layers. In the $\mathrm{N}_{2}$-shielded wall, when comparing the nonreheated layer with the reheated layers, no secondary austenite is observed in the reheated layers, but the growth/coarsening of intragranular, Widmanstätten, and intergranular austenite is very clear. Similar to the Ar-shielding, there does not seem to be a big difference in the evolution of the microstructure within the reheated layers, and definitely, austenite is visibly more present in the $\mathrm{N}_{2}$-shielded wall.

No signs of sigma-phase were found during the microstructural inspection.

Figure 11 shows representative microstructures for a vertical line (location 6 in Fig. 4) that crosses the 10 layers in each one of the 4 blocks (B-A-AD, B-A-HT, B-N-AD, B-N-HT). As already observed in the walls, the macros showed an epitaxial growth in the fusion boundaries. In the blocks, the outer bead profiles presented a convex shape, as also observed in the walls, whilst the inner beads in the blocks showed a concave profile.



Fig. 5 Cross-section of the 10-layer, 5-bead block showing two lines of OES spots. Line 1 shows the locations close to the substrate, and line 2 shows the locations close to the top
There is a high similarity between the microstructural features observed in the as-deposited Ar-shielded and $\mathrm{N}_{2-}$ shielded wall layers and the microstructures observed in the as-deposited blocks. In the as-deposited Ar-shielded deposits it is possible to observe very fine secondary austenite and the growth or coarsening of the primary austenite (intragranular, Widmanstätten, and intergranular). In the as-deposited $\mathrm{N}_{2-}$ shielded blocks no secondary austenite can be observed in the reheated layers, but the growth/coarsening of intergranular, Widmanstätten, and intragranular austenite is evident. In the heat-treated Ar-shielded and $\mathrm{N}_{2}$-shielded blocks, the originally elongated morphology of Widmanstätten and intergranular austenite is coarsened and the blocky intragranular austenite morphology shows rounded corners in a kind of "globular" morphology. No signs of sigma-phase were found during the microstructural inspection.

\section{Discussion}

\subsection{Oxygen content in LMDw deposits}

In $\mathrm{LMDw}$, the molten metal is exposed to the gas-shielding environment, except for the contact area with the substrate or previous layer. That makes a substantial difference when comparing to welding in a joint, where the base material surrounds the weld pool and there is less surface area of molten metal exposed to the environment. This fact, together with the

Table 4 Oxygen content measured by combustion technique in the deposited metal

\begin{tabular}{lll}
\hline Sample ref. & Description & Oxygen content $(\mathrm{ppm})$ \\
\hline N1 & Single-bead, $\mathrm{N}_{2}$-shielded & 117 \\
A1 & Single-bead, Ar-shielded & 111 \\
N10 & 10-layer wall, $\mathrm{N}_{2}$-shielded & 160 \\
A10 & 10-layer wall, Ar-shielded & 112 \\
\hline
\end{tabular}




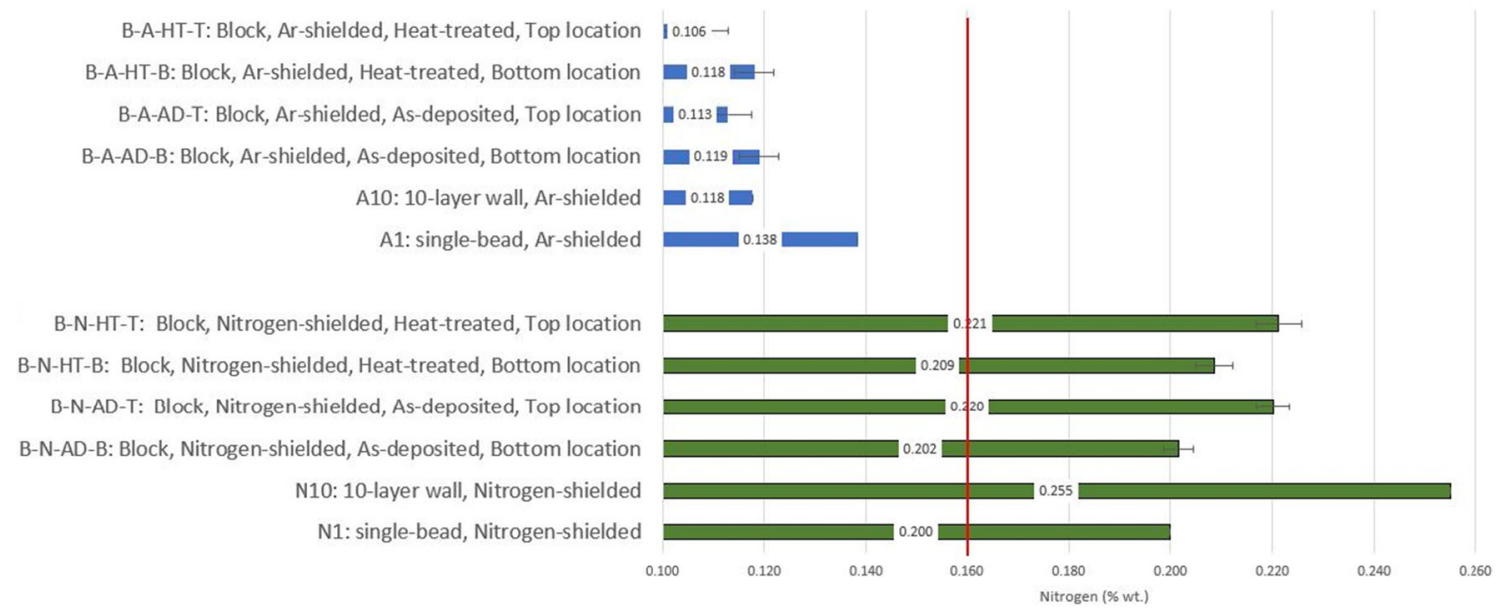

Fig. 6 Nitrogen content (wt\%) measured in the single-bead samples (A1, $\mathrm{N} 1)$, in the 10-layer wall samples (A10, N10) and in the block samples (B-A-HT, B-A-AD, B-N-HT, B-N-AD). The block designations end in T or in $\mathrm{B}$, referring to the location of the measurement and being top and

severe reduction in impact toughness that duplex stainless steel experiences if oxygen content is higher than about $200 \mathrm{ppm}$ [31], motivated the interest to investigate the oxygen content in the single-bead and 10-layer wall specimens. The results in Table 4 showed that in all cases the oxygen values were between 111 and $160 \mathrm{ppm}$. These values were compared with oxygen contents reported in the literature [31,34] for bottom respectively. Error bars depict the standard deviation of the average value obtained in the block samples from the individual measurements per location (top, bottom). The nitrogen content in the wire is represented by the vertical red line

single pass conventional GTA 50-150 ppm and for flux cored wire welding (FCW) 1300 ppm. In addition, Fig. 13 illustrates a comparison of the results in the project with the oxygen content for multi-pass welding of super-duplex stainless steels [35]. The comparison reveals that the oxygen content in the laser metal deposited metal produced in the study was on the same level as the oxygen contained in multi-pass GTA and
Fig. 7 Average austenite content (percentage) measured in the single-bead samples (labeled as A1 and N1) and in the 10-layer wall samples (labeled as A10 and N10). The number after the dash in the wall samples corresponds to the layer number as described in Fig. 4. This figure reveals higher austenite content when using $\mathrm{N}_{2}$ shielding than when using Arshielding

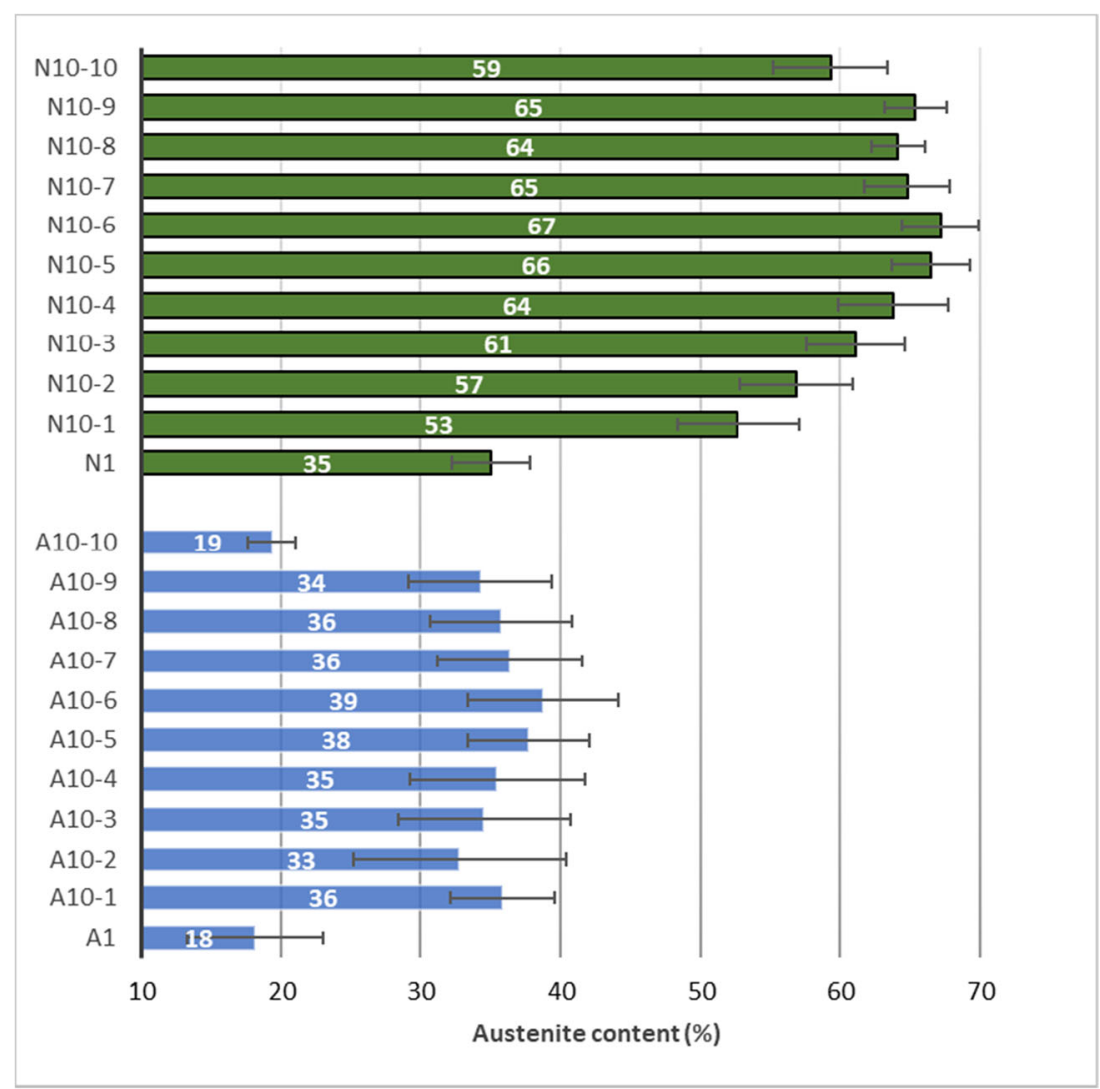




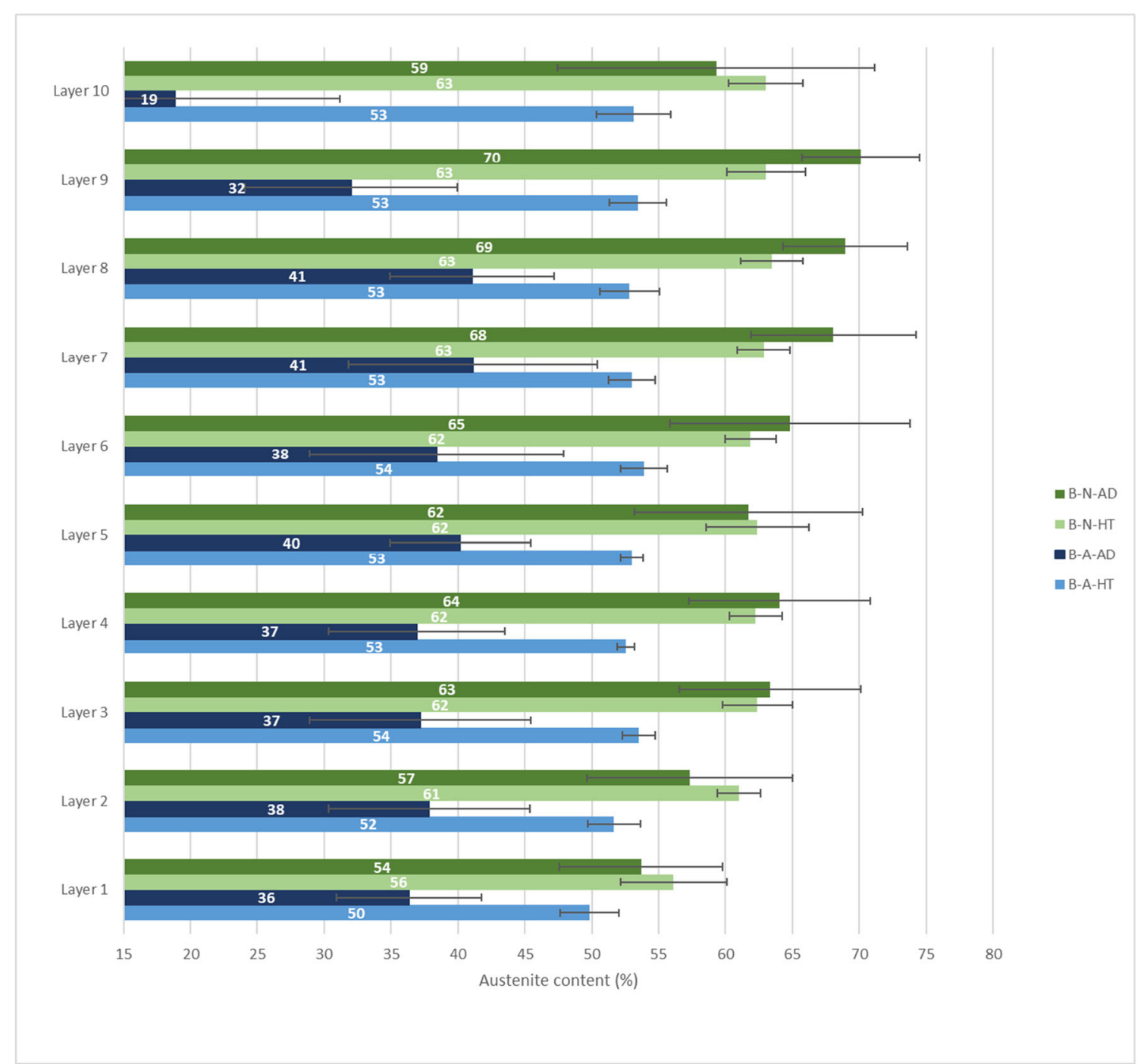

Fig. 8 Average austenite content (percentage) layer per layer in the block samples. Error bars depict the standard deviation of the average value obtained from the 8 individual locations evaluated along the layer. Notation and legend used as per described in Table 3. This figure illustrates that the austenite content is higher when using nitrogen as a shielding gas compared with when using argon. Besides, the standard deviation of the average value in each layer is lower in the heat-treated blocks than in the as-deposited blocks gas metal arc welding (GMA), and below the oxygen contents measured for the flux-cored welding processes FCW and submerged arc welding (SAW). Therefore, it can be concluded that the duplex stainless steel deposited with LMDw process does not have a special susceptibility to oxygen pick-up, provided that the process is properly shielded.

\subsection{Influence of shielding gas on nitrogen loss}

The AWS standard A5.9M establishes a range for min-max nitrogen contents of $0.14 \mathrm{wt} \%$ and $0.20 \mathrm{wt} \%$, respectively, for the 2209 duplex wire. The specific batch used in this study contained $0.16 \mathrm{wt} \%$ nitrogen (Table 1 ).
The results (Fig. 6) clearly showed that nitrogen loss is a fact when using Ar-shielding, as the deposited material contained less nitrogen than the wire. For the single-bead, the relative nitrogen loss was in the range of $14 \%$ and the relative loss of nitrogen in the top of the 10-layer wall was found to be $26 \%$. In the case of the blocks, it was also evident that the top layers contained less nitrogen than the bottom layers (relative reduction in the range 4-10\%) and from the bottom line compared with the nitrogen wire, there is a $25 \%$ relative loss in nitrogen content. The nitrogen loss phenomenon has been already reported in arcwelding [36, 37] and in WAAM [16] when using Arshielding. The driving force explaining the nitrogen loss observed is the need for the system (molten pool - 


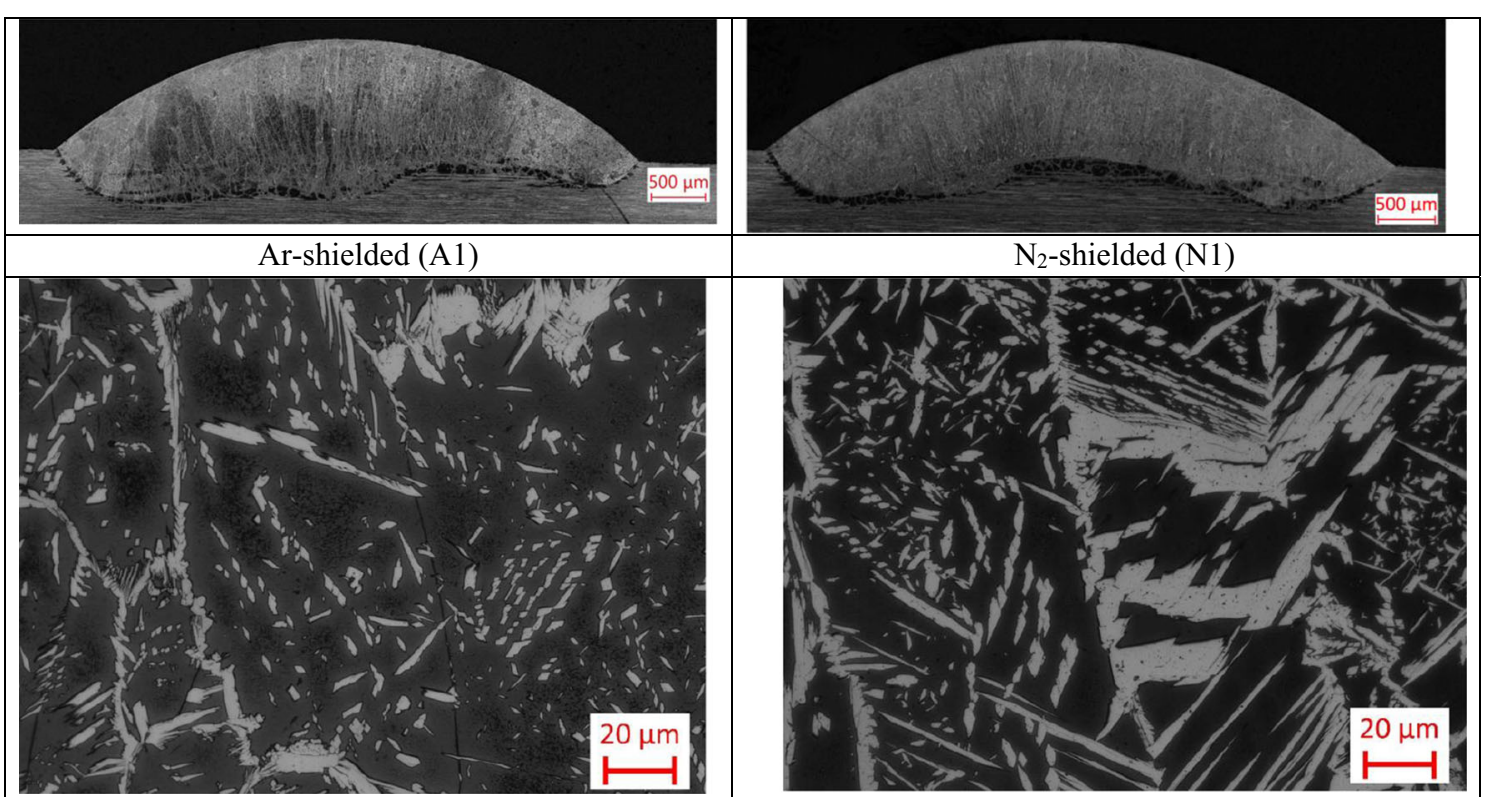

Fig. 9 Upper micrographs: cross-section of the single-bead deposits, $\mathrm{Ar}$ shielded (A1) and $\mathrm{N}_{2}$-shielded (N1). Lower micrographs: representative microstructure observed for each one of the samples. Ferrite and nitrides

shielding environment) to reach the compositional equilibrium. When there is no nitrogen in the shielding environment, the nitrogen which is contained in the melt pool tends to escape from the material with the aim of increasing the nitrogen content in the environment and therefore to achieve an equilibrium in composition. That explains why nitrogen loss increases with increasing the number of deposited beads under the Ar-shielding conditions. To compensate that loss and to increase the austenite content and therefore to achieve higher impact toughness, it is commonly suggested to add up to $2 \%$ nitrogen to the argon shielding. The high surface area of molten metal exposed to the environment in AM processes can intensify the nitrogen loss phenomenon.

On the other hand, the results in this work (Fig. 6) showed that the LMDw specimens that were nitrogen-shielded exceeded the $0.16 \mathrm{wt} \%$ of nitrogen contained in the wire. In fact, the nitrogen content in the samples is within the range of super-duplex 2509 alloy (0.20-0.30 wt $\%)$. When increasing the number of beads, the nitrogen content increased but it was never exceeding $0.26 \mathrm{wt} \%$ (when measuring by LECO) or $0.23 \mathrm{wt} \%$ (when measuring by OES). As previously explained, the resulting nitrogen content in the deposited material is governed by the balance between the molten pool and the surrounding atmosphere. Therefore, when pure nitrogen is used as a shielding gas, the trend of the molten pool is to pick up nitrogen to achieve the compositional equilibrium, and higher nitrogen content is found when increasing the number of beads. Therefore, the use of pure nitrogen shielding seems to be a convenient way to avoid or limit nitrogen loss in LMDw. are dark whilst austenite is bright. Differences in nitrides, intergranular ferrite, Widmanstätten austenite, and intragranular austenite are revealed

\subsection{Influence of the shielding gas on the microstructure and phase balance}

The results in chapter 3.3 revealed that austenite content is nearly doubled when $\mathrm{N}_{2}$-shielding is used in comparison to Ar-shielding in both wall and block geometries (Figs. 7 and 8 ). It is worth noting that the austenite values measured are in compliance with Norsok standard M-601 [38] for $22 \% \mathrm{Cr}$ duplex stainless steel weldments, with austenite in the range of 30 to $70 \%$.

It is well known that nitrogen is an austenite promoter and that an increase in austenite is beneficial for corrosion resistance and for better impact toughness in the deposited material $[36,37]$. The higher the nitrogen content, the higher the temperature at which the ferrite to austenite transformation starts [39]. That implies that the use of nitrogen shielding led to an increase in the austenite content after solidification (primary austenite).

In addition, regardless of which shielding gas is used, the reheating of the deposited layers enables nitrogen diffusion from ferrite to austenite and promotes the formation of secondary austenite and the growth/coarsening of Widmanstätten and intergranular austenite [40-44], as it was observed in this work.

Nitrides were scarcely found in the $\mathrm{N}_{2}$-shielded layers, whilst they were massively found in the Ar-shielded deposits. The higher austenite content in the $\mathrm{N}_{2}$-shielded layers and the higher solubility of nitrogen in the austenite phase can be the main reason. As previously reported, no signs of sigma-phase were found during the microstructural inspection of the asdeposited samples. It is possible that with the current $\mathrm{LMDw}$ settings established for the preparation of these specimens, the 




Fig. 10 First row: cross section of the 10-layer walls, Ar-shielded (left) designated as $\mathrm{A} 10$ and $\mathrm{N}_{2}$-shielded (right) designated as N10. Below, representative microstructures observed in vertical line crossing from layer 1 to layer 10. Ferrite and nitrides are dark whilst austenite is bright. In the reheated Ar-shielded layers, secondary austenite is visible whilst that is not observed in the reheated $\mathrm{N}_{2}$-shielded layers, but instead the growth/coarsening of intragranular, Widmanstätten, and intergranular austenite is evident. No significant difference in the evolution of the microstructure within the reheated layers can be found in any of the walls 


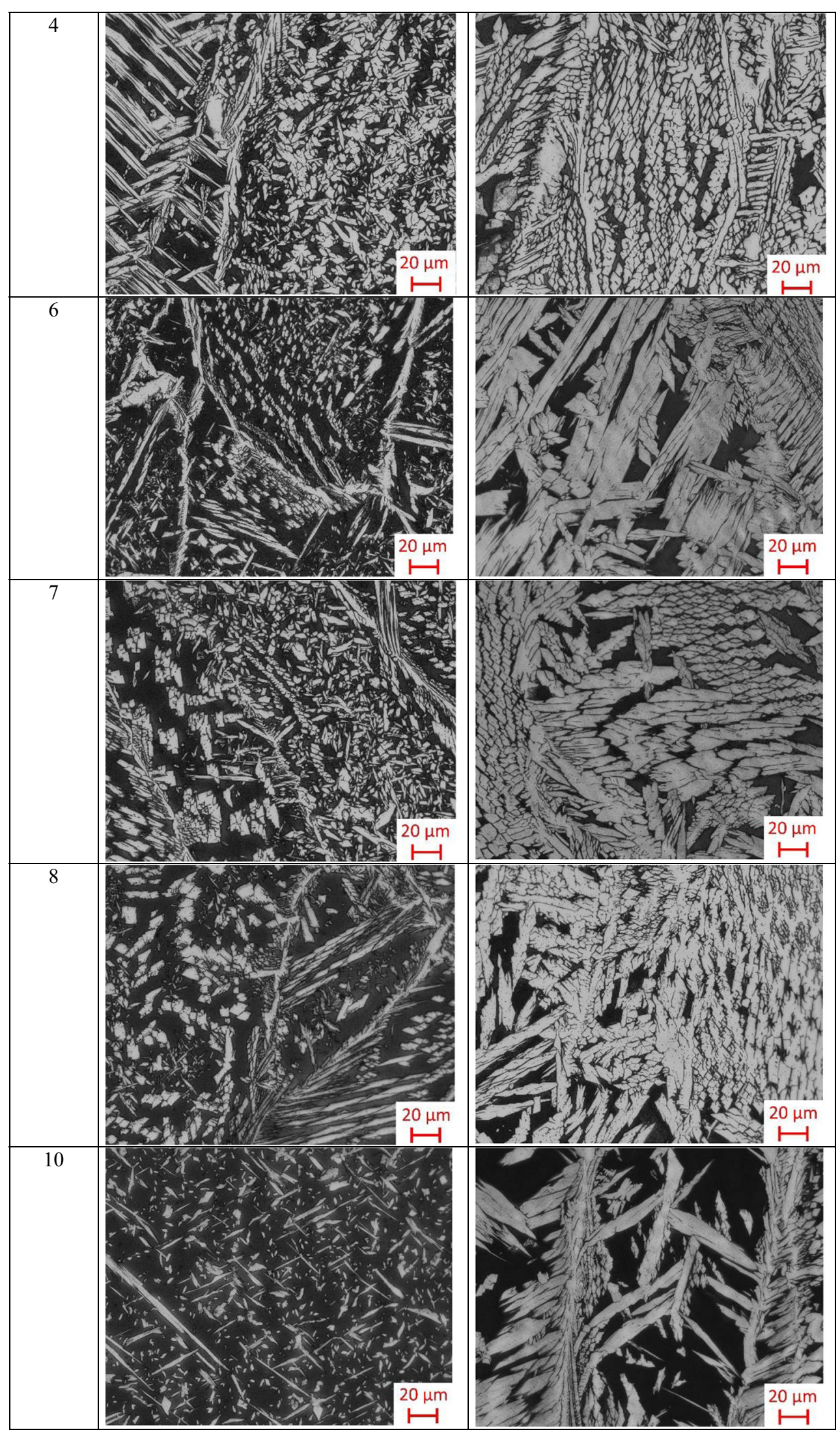

Fig. 10 (continued) 


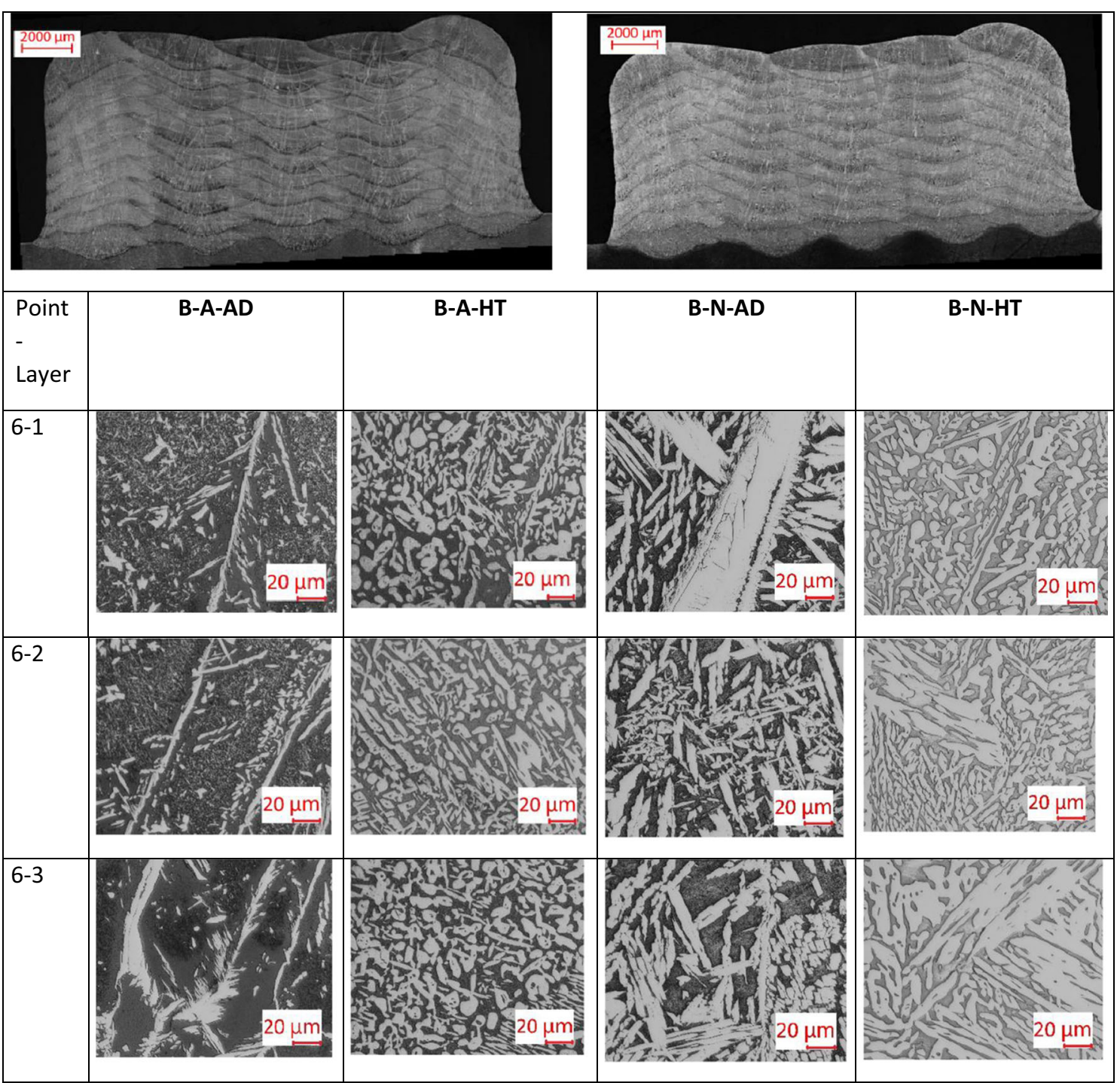

Fig. 11 First row: Cross section of the as-deposited 10-layer $\times$ 5-bead blocks, Ar-shielded (left) as deposited (B-A-AD) and heat-treated (B-A$\mathrm{HT}$ ) and $\mathrm{N}_{2}$-shielded (right) as deposited (B-N-AD) and heat-treated (B$\mathrm{N}-\mathrm{HT}$ ). Below, representative microstructures observed in the same vertical line crossing from layer 1 to layer 10 . Ferrite and nitrides are dark whilst austenite is bright. Very fine secondary austenite and the growth or coarsening of the primary austenite (intragranular, Widmanstätten, and

previously deposited layers did not reach the necessary temperature and time to promote its formation [8]. The importance of monitoring the thermal history during the deposition in additive manufacturing is crucial to explain the resulting microstructure, as it will be also shown in chapter 4.5.

The average austenite values in the layers showed a very low spread within each shielding gas used: from 33 to $39 \%$ in Ar-shielded and from 53 to $67 \%$ in the $\mathrm{N}_{2}$-shielded. This low spread in the austenite content together with the evaluation layer per layer of the microstructural features indicates that the walls and the blocks have a repetitive/consistent microstructure all along the build-up. intergranular) is observed in the as-deposited Ar-shielded microstructures. In the as-deposited N2-shielded blocks no secondary austenite can be observed, but the growth/coarsening of intergranular, Widmanstätten, and intragranular austenite is evident. In both heattreated blocks, the originally elongated morphology of Widmanstätten and intergranular austenite is coarsened and the blocky intragranular austenite morphology shows rounded corners in a "globular" morphology

The results in terms of microstructure and phase balance for the as-deposited walls and blocks for each shielding gas are very similar. That is a sign that the process control developed for the project has been able to produce the different geometries consistently and that it is ready to proceed with the build-up of more complex geometries.

\subsection{Influence of the heat treatment on the microstructure and austenite content}

The heat treatment resulted in an increase of the austenite content: from $36-41 \%$ to $52-54 \%$ when Ar was used for 


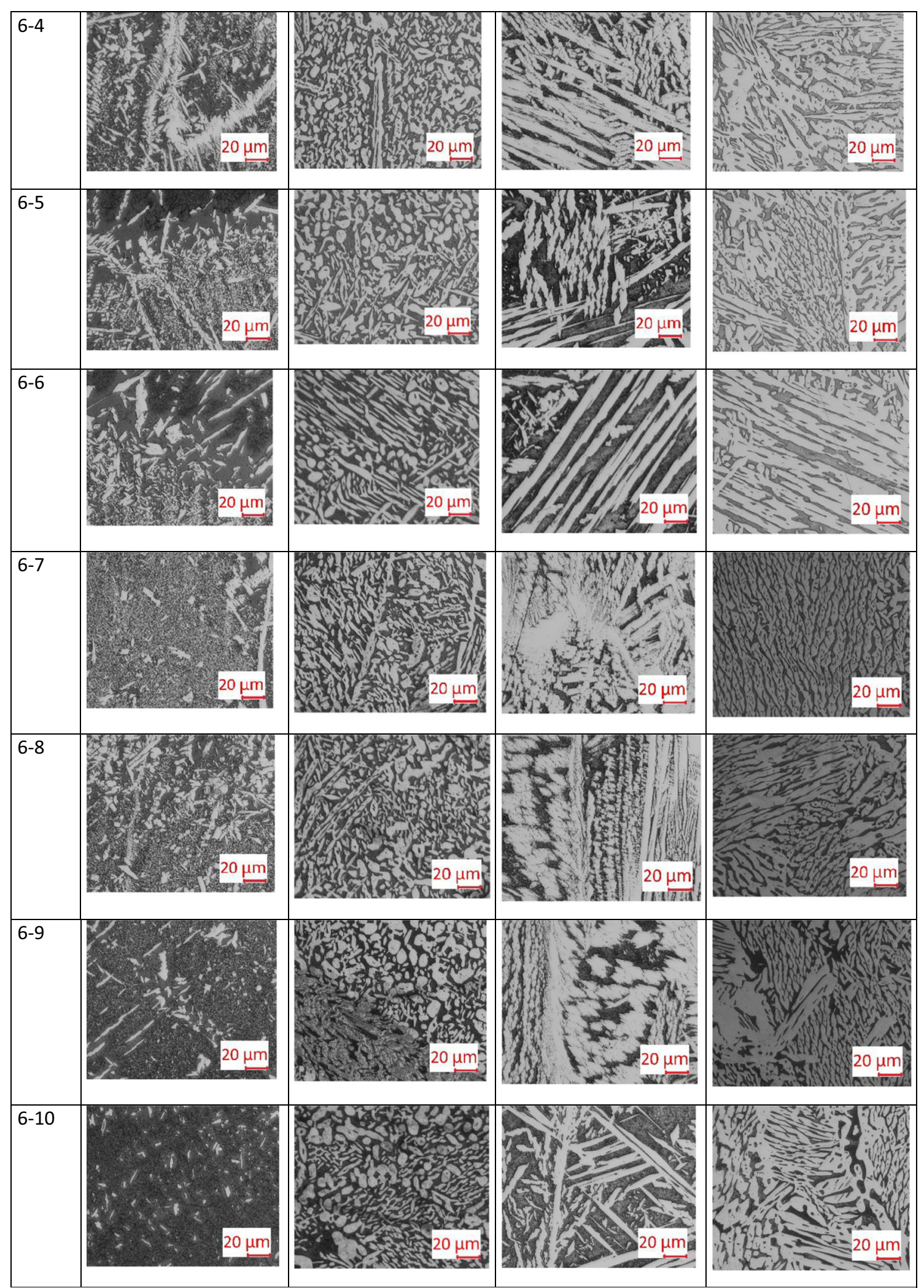

Fig. 11 (continued) 
Fig. 12 Higher magnification image of Fig. 9 showing two ferrite grains separated by elongated intergranular austenite. Nitrides are located in the intragranular areas and they appear as small dimples (see circles), resulting from their partial or total dissolution by the etchant

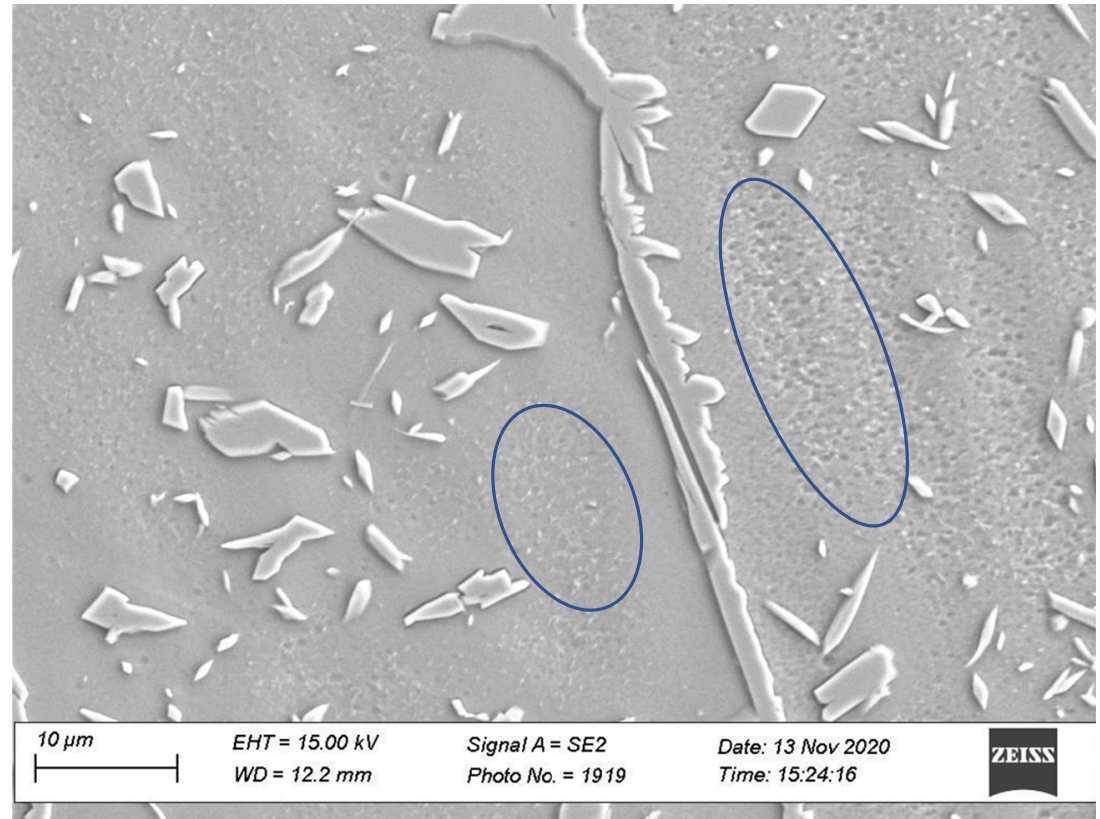

shielding. That represents a $38 \%$ relative increase in austenite. When $\mathrm{N}_{2}$ was used, the maximum difference found was from $63 \%$ in the as-deposited condition to $70 \%$ in the heat-treated one, which represents only an $11 \%$ relative increase. The explanation for the lower relative increase of austenite when $\mathrm{N}_{2}$-shielding deposit was heat-treated is related to the higher nitrogen content in the $\mathrm{N}_{2}$-shielded material. In this case, there is initially a higher austenite content. The material is already closer to the austenite content that could be thermodynamically achieved in equilibrium, and therefore, the driving force to form austenite during the heat treatment is lower.

Regarding the austenite morphology, due to the heat treatment, the originally elongated morphology of Widmanstätten and intergranular austenite was coarsened and the blocky intragranular austenite morphology showed rounded corners in a "globular-like" morphology. This globular morphology was observed in heat-treated duplex and super-duplex stainless steels $[33,45]$ and the driving force could be the reduction of the interface surface energy in the austenite-ferrite boundaries.

It is important to note that the austenite values measured in the heat-treated samples showed lower standard deviation than the austenite values in the as-deposited blocks. That is interpreted as a sign of higher homogeneity in the microstructure.

As described in the methodology chapter, the solution annealing temperature of $1100{ }^{\circ} \mathrm{C}$ was decided based on the literature [33] and on Thermo-Calc calculations, predicting the formation of sigma-phase at temperatures below $1008^{\circ} \mathrm{C}$ for the specific chemical composition of the wire used. Therefore, as expected, no signs of sigma-phase were found
Fig. 13 Comparison of the oxygen content in the deposited material by using different welding processes (in green) [35] and by LMDw (in blue the $\mathrm{N}_{2-}$ shielded and in orange the Arshielded samples). The number at the end of the designation shows the number of welding passes or number of deposited beads in the LMDw specimens. The LMDw deposits contain oxygen at the same level as GTA and GMA weldments

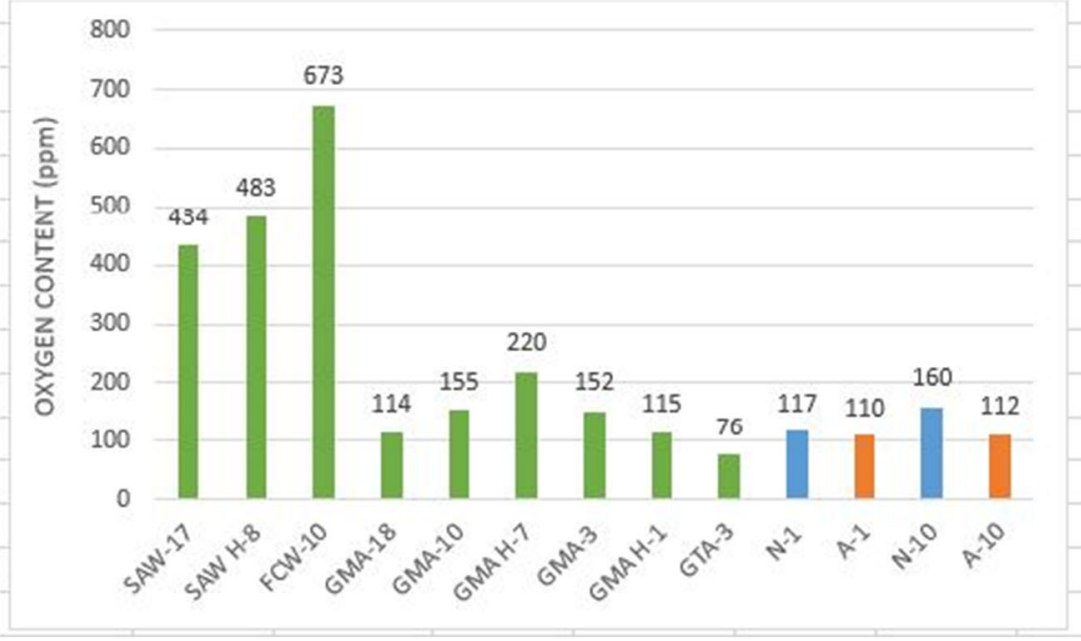


during the microstructural inspection of the heat-treated specimens.

To check if Thermo-Calc could be a good tool to predict the ferrite content achieved with the heat treatment, the ferrite fraction versus the nitrogen content at $1100{ }^{\circ} \mathrm{C}$ was plotted for the specific composition of the wire (Fig. 14). The $\mathrm{N}_{2^{-}}$ shielded specimens had a nitrogen content between 0.20 and $0.26 \mathrm{wt} \%$, whilst the Ar-shielded specimens had a nitrogen content between 0.10 to $0.14 \mathrm{wt} \%$ (data from Fig. 6). For those nitrogen contents, Fig. 14 predicts ferrite from 23 to $30 \%$ (austenite $70-77 \%$ ) for the $\mathrm{N}_{2}$-shielded deposits and ferrite from 37 to $44 \%$ (austenite 56-63\%) for the Ar-shielded ones. When comparing these values with the experimental austenite measurements in Fig. 8, it is clear that ThermoCalc gives a reasonable approach.

\subsection{Bead profiles in the deposits}

It is well-known that the thermal gradients (temperatures and cooling rates) influence the resulting microstructure of the deposited materials. In the experiments presented in this paper, the temperature distribution is not known. However, the differences observed in the bead profiles seem to indicate heterogeneities in the temperatures of the substrate.

A difference is observed in the concavity and convexity of the beads' profile. A concave profile is observed in the cases where the beads are deposited on the substrate plate and on previous layers in the block. A convex profile is observed in the wall beads and in the outer beads of the block (Fig. 11). Some authors noticed about the melt pool convexity in multibead AM using a laser source and tried to explain the phenomenon. Gharbi et al. [46] proposed that for a wall, the negative Marangoni flow pushes the central part of the melt-pool upwards due to an increase of the temperature gradient in the lateral direction. However, Lee [47] underlined the importance of the surface shape of the previously deposited layer, as it will have an influence on the melt pool flow of the subsequent

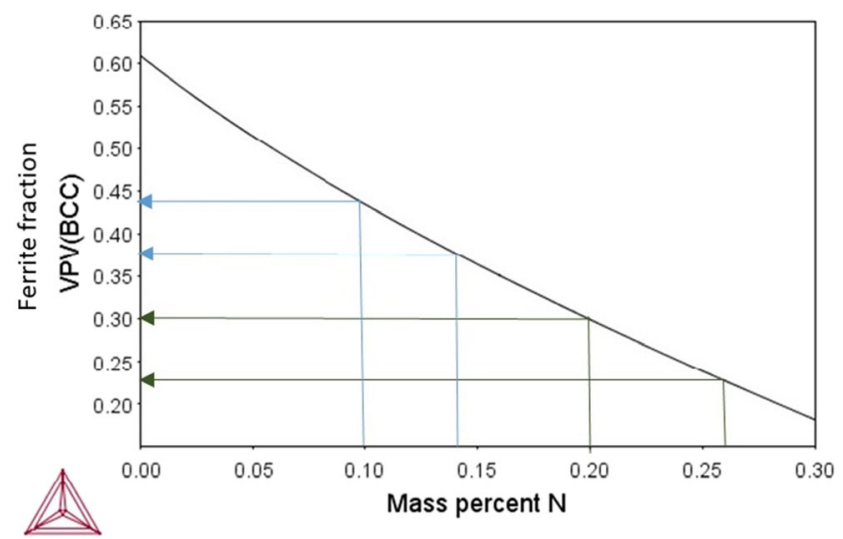

Fig. 14 Ferrite fraction versus nitrogen content diagram at $1100^{\circ} \mathrm{C}$. Blue lines correspond to nitrogen contents of Ar-shielded samples and green lines to nitrogen contents of $\mathrm{N}_{2}$-shielded samples. layer. Another element to consider is the different spatial distribution of the heat transfer. When the deposition is on the substrate plate and on the inner layers of the block, the heat transfer mainly occurs in the three-dimensions, whilst it occurs preferentially in two dimensions (vertical and along the deposition direction) in the wall and in the outer beads of the block. At the end of the day, the resulting bead geometry is a consequence of the balance of the different forces experienced by the liquid in the melt pool and those forces are strongly dependent on the temperature distribution in the material. Therefore, the local differences in the thermal history (temperature gradients, cooling rates) among the beads in the wall, the outer beads and the inner beads of the block, could explain the differences in the concavity and convexity of the bead profiles. More work is needed for a better understanding of this aspect.

\section{Conclusions}

In this work, the influence of $\mathrm{Ar}$ and $\mathrm{N}_{2}$ shielding gases in LMDw of duplex stainless steel was evaluated in terms of nitrogen loss and on the microstructure and austenite content of different deposited geometries: single bead, 10-bead walls and 5 bead $\times 10$ layers blocks. The evolution of the microstructure in the build-up direction of the $\mathrm{Ar}$ and $\mathrm{N}_{2}$-shielded blocks was compared in the heat-treated and as-deposited conditions. In addition, the susceptibility for oxygen pick-up in the LMDw deposits was analyzed.

- The oxygen contents of the duplex stainless steel laser metal deposits were found to be in the range of GTA and GMA weldments. Specimens produced by LMDw with proper shielding conditions are therefore not more susceptible to oxygen pick up than weldments produced by gas-shielded arc welding processes.

- Nitrogen loss occurs in the LMDw specimens when using Ar-shielding, and the loss increases when increasing the number of deposited layers. However, the use of $\mathrm{N}_{2}-$ shielding was found to be a convenient way to avoid nitrogen loss in LDMw.

- Austenite content is nearly doubled by using $\mathrm{N}_{2}$-shielding instead of Ar-shielding; from 33 to $39 \%$ when Ar-shielded and from 53 to $67 \%$ when $\mathrm{N}_{2}$-shielded. This low variation in the austenite content together with the evaluation layer per layer of the microstructural features confirms a repetitive/consistent microstructure all along the build-up.

- The heat treatment increased the austenite content in all cases for both shielding gases. When using Ar, the relative increase of austenite fraction was $38 \%$, whilst when using $\mathrm{N}_{2}$, the maximum relative increase was $11 \%$. The heat treatment also increased the homogeneity of the microstructure.

- The similarity in microstructure and phase balance for the as-deposited walls and blocks for each shielding gas 
shows a stable and consistent LMDw process suitable for build-up of more complex geometries.

Acknowledgments Open access funding provided by University West. Petter Hagqvist and Mats Högström are gratefully acknowledged for their work in the process control, and Sten Wessman is especially acknowledged for his support with computational thermodynamics. Isabelle Choquet is sincerely acknowledged for her assistance with fluid mechanics.

Funding This research project was supported by grants from the Swedish Knowledge Foundation project SAMw (20170060).

Open Access This article is licensed under a Creative Commons Attribution 4.0 International License, which permits use, sharing, adaptation, distribution and reproduction in any medium or format, as long as you give appropriate credit to the original author(s) and the source, provide a link to the Creative Commons licence, and indicate if changes were made. The images or other third party material in this article are included in the article's Creative Commons licence, unless indicated otherwise in a credit line to the material. If material is not included in the article's Creative Commons licence and your intended use is not permitted by statutory regulation or exceeds the permitted use, you will need to obtain permission directly from the copyright holder. To view a copy of this licence, visit http://creativecommons.org/licenses/by/4.0/.

\section{References}

1. Industrial and Regional valorization of FoF Additive Manufacturing Projects (Horizon 2020). https://cordis.europa.eu/ project/id/636882

2. AM-Motion, A strategic approach to increasing Europe's value proposition for Additive Manufacturing technologies and capabilities (Horizon 2020) http://am-motion.eu/

3. The Integradde project (Horizon 2020) http://www. integraddeproject.eu/

4. DebRoy T, Wei HL, Zuback JS, Mukherjee T, Elmer JW, Milewski JO, Beese AM, Wilson-Heid A, De A, Zhang W (2018) Additive manufacturing of metallic components- Process, structure and properties. Progress in Materials Science 92:112-224

5. Karlsson L, Arcini H (2012) Low energy input welding of duplex stainless steels. Welding in the World 56:41-47. https://doi.org/10. 1007/BF03321380

6. Karlsson L (2012) Welding duplex stainless steels - a review of current recommendations. Welding in the World 56:65-76

7. Karlsson L (1999) Intermetallic phase precipitation in duplex stainless steels and weld metals metallurgy, influence on properties and welding aspects. Welding in the World 43:20-41

8. Hosseini V, Karlsson L, Engelberg D, Wessman S (2018) Timetemperature-precipitation and property diagrams for super duplex stainless steel weld metals. Welding in the World 62:517-533. https://doi.org/10.1007/s40194-018-0548-z

9. Davidson K, Singamneni S (2016) Selective laser melting of duplex stainless steel powders: an investigation. Materials and Manufacturing Processes 31:1543-1555. https://doi.org/10.1080/ 10426914.2015.1090605

10. Hengsbach F, Koppa P, Duschik K, Holzweissig M-J, Burns M, Nellesen J, Tillmann W, Tröster T, Hoyer K-P, Schaper M (2017) Duplex stainless steel fabricated by selective laser meltingmicrostructural and mechanical properties. Materials and Design $133: 136-142$
11. Saeidi K, Kevetkova L, Lofaj F, Shen Z (2016) Novel ferritic stainless steel formed by laser melting from duplex stainless steel powder with advanced mechanical properties and high ductility. Materials Science \& Engineering A 665:59-65

12. Papula S, Song M, Pateras A, Chen X-B, Brandt M, Easton M, Yagodzinskyy Y, Virkkunen I, Hänninen H (2019) Selective laser melting of duplex stainless steel 2205: Effect of post-processing heat treatment on microstructure, mechanical properties, and corrosion resistance. Materials 12:2468. https://doi.org/10.3390/ ma12152468

13. Woo W, Kim D-Y, Kingston EJ, Luzin V, Salvemini F, Hill MR (2019) Effect of interlayers and scanning strategies on throughthickness residual stress distributions in additive manufactured ferritic-austenitic steel structure. Materials Science \& Engineering A 744:618-629. https://doi.org/10.1016/j.msea.2018.12.078

14. Posch G, Chladil K, Chladil H (2017) Material properties of CMTmetal additive manufactured duplex stainless steel blade-like geometries. Welding in the World 61:873-882

15. Lervåg $\mathrm{M}$, Sorensen $\mathrm{C}$, Roberstad A, Bronstad B-M, Nyhus B, Eriksson M, Aune R, Ren X, Bunaziv AO-M, I. (2020) Additive manufacturing with superduplex stainless steel wire by CMT process. Metals 10:272. https://doi.org/10.3390/met10020272

16. Hosseini V, Högström M, Valiente Bermejo MA, Stridh L-E, Karlsson L (2019) Wire-arc additive manufacturing of a duplex stainless steel: thermal cycle analysis and microstructure characterization. Welding in the World 63:975-987. https://doi.org/10.1007/ s40194-019-00735-y

17. Zhang X, Wang K, Zhou Q, Kong J, Peng Y, Ding J, Diao C, Yang D, Huang Y, Zhang T, Williams SW (2020) Element partitioning and electron backscatter diffraction analysis from feeding wire to as-deposited microstructure of wire and arc additive manufacturing with duplex stainless steel. Materials Science \& Engineering A 773: 138856

18. Eriksson $\mathrm{M}$, Lervåg $\mathrm{M}$, Sorensen $\mathrm{C}$, Roberstad A, Bronstad B-M, Nyhus B, Aune R, Ren X, Akselsen O-M (2018) Additive manufacturing of superduplex stainless steel using WAAM. MATEC Web of Conferences 188:03014. https://doi.org/10.1051/ matecconf/201818803014

19. Stützer J, Totzauer T, Wittig B, Zinke M, Jüttner S (2019) GMAW cold wire technology for adjusting the ferrite-austenite ratio of wire and arc additive manufactured duplex stainless steel components. Metals 9:564. https://doi.org/10.3390/met9050564

20. Hejripour F, Binesh F, Hebel M, Aidun DK (2019) Thermal modeling and characterization of wire arc additive manufactured duplex stainless steel. Journal of Materials Processing Technology 272:58-71

21. Topic A, Garasic I, Juric I, Knezovic N (2019) Investigation of properties of WAAM produced duplex stainless steel part. In: International Conference on materials: corrosion, heat treatment, testing and tribology. MTECH 2019, pp 176-187

22. Pickle T, Henry N, Morriss P, Tennis L, Wagner D, Baumer RE (2019) Root pass microstructure in superduplex stainless steel multipass welds. Welding Journal 98(5):123s-134s. https://doi. org/10.29391/2019.98.010

23. Cederberg E, Hosseini VA, Kumara C, Karlsson L (2020) Physical simulation of additively manufactured superduplex stainless steelsmicrostructure and properties. Additive Manufacturing 34:101269. https://doi.org/10.1016/j.addma.2020.101269

24. Landowski M (2019) Influence of parameters of laser beam welding on structure of 2205 duplex stainless steel. Advances in Materials Science, 19, 1 (59), https://doi.org/10.2478/adms-2019-0002

25. Ghosh A, Misra D, Acharyya SK (2019) Experimental and numerical investigation on laser welding of 2205 duplex stainless steel. Lasers in Manufacturing and Materials Processing 6:228-246. https://doi.org/10.1007/s40516-019-00090-2

26. Soltysiak R, Gietka T, Soltysiak A (2018) The effect of laser welding power on the properties of the joint made of 1.4462 duplex 
stainless steel. Advances in Mechanical Engineering 10(1):1-12. https://doi.org/10.1177/1687814017751949

27. Magalhaes AS, Magalhaes CHXM, De Lima MSF, Cruz J, Godefroid LB, Bertazzoli R, De Faria GL (2020) Effect of PWHT on laser-welded duplex stainless steel. Welding Journal 99(7):185s-202s. https://doi.org/10.29391/2020.99.018

28. Keskitalo M, Mäntyjärvi K, Sundqvist J, Powell J, Kaplan AFH (2015) Laser welding of duplex stainless steel with nitrogen as shielding gas. Journal of Materials Processing Technology 216: 381-384

29. Kolenic F, Kovac L, Drimal D (2011) Effect of laser welding conditions on austenite/ferrite ratio in duplex stainless steel 2507 welds. Welding in the World 55:19-25

30. Jeon S-H, Hur DH, Kim H-J, Park Y-S (2014) Influence of oxygen content on the inclusion formation and pitting corrosion resistance of hyper duplex stainless steels. Materials Transactions 55(12): $1872-1877$

31. Moon YH, Kim HT, Hur SD (1987) Effect of oxygen content on impact toughness of austenitic and duplex stainless steel weld metal. Journal of the Korean Welding Society 5(3):38-45

32. Hosseini VA, Hurtig K, Eyzop D, Östberg A, Janiak P, Karlsson L (2019) Ferrite content measurement in super duplex stainless steel welds. Welding in the World 63(2):551-563

33. Kotecki DJ (1989) Heat treatment of duplex stainless steel weld metals. Welding Journal 68(11):431s-441s

34. Metrode Products Ltd (2005) Duplex \& superduplex stainless steels, properties and test requirements. Issue 1. 16 pages

35. Valiente Bermejo MA, Karlsson L, Svensson L-E, Hurtig K (2017) TrueTherm project report: determining local thermal cycles in multi-pass superduplex stainless steels welds and effects on microstructure and properties. Högskolan Väst. 66 pages

36. Sales AM, Westin EM, Jarvis BL (2017) Effect of Nitrogen in shielding gas of keyhole GTAW on properties of duplex and superduplex welds. Welding in the World 61(6):1133-1140. https://doi.org/10.1007/s40194-017-0486-1

37. Zhang Z, Jing H, Xu L, Han Y, Zhao L (2016) Investigation on microstructure evolution and properties of duplex stainless steel joint multi-pass welded by using different methods. Materials and Design 109:670-685

38. Standards Norway. (2004). NORSOK Standard M-601. Rev. 4, Welding and inspection of piping, $20 \mathrm{p}$.
39. Hosseini V, Karlsson L (2019) Physical and kinetic simulation of nitrogen loss in high temperature heat affected zone of duplex stainless steels. Materialia 6:100325. https://doi.org/10.1016/j.mtla. 2019.100325

40. Valiente Bermejo MA, Hurtig K, Eyzop D, Karlsson L (2019) A new approach to the study of multi-pass welds-microstructure and properties of welded $20 \mathrm{~mm}$ thick superduplex stainless steel. Applied Sciences 9:1050. https://doi.org/10.3390/app9061050

41. Hosseini VA, Hurtig K, Karlsson L (2020) Bead by bead study of a multipass shielded metal arc-welded super-duplex stainless steel. Welding in the World 64(2):283-299. https://doi.org/10.1007/ s40194-019-00829-7

42. Ramirez AJ, Brandi SD, Lippold JC (2004) Investigation on microstructure evolution and properties of duplex stainless steel joint multi-pass welded by using different methods. Science and Technology of Welding and Joining 9(4):301-313

43. Garzon CM, Ramirez AJ (2006) Growth kinetics of secondary austenite in the welding microstructure of a UNS S32304 duplex stainless steel. Acta Materialia 54:3321-3331

44. Liu X, Ding X-P, He Y-L, Li L, Song HM, Hu JC (2010) Experimental study and kinetic calculation on migration of $\gamma / \alpha$ interface boundary during high temperature aging for 2205 duplex stainless steel. Journal of Iron and Steel Research International 17(8):45-49

45. Park S, Shin B-H, Park J, Kim D, Chung W (2019) Effect of austenite morphology on the electrochemical properties of super duplex stainless UNS S 32750. International Journal of Electrochemical Science 14:5386-5395

46. Gharbi M, Peyre P, Gorny C, Carin M, Morville S, Le Masson P, Carron D, Fabbro R (2013) Influence of various process conditions on surface finishes induced by the direct metal deposition laser technique on a Ti-6Al-4V alloy. J Mater Process Technol 213(5): 791-800

47. Lee Y (2015) Simulation of laser additive manufacturing and its applications. Chapter 4: Simulation of transport phenomena and melt pool shape for multiple layer additive manufacturing (p. 71-95). $\mathrm{PhD}$ dissertation. The Ohio State University. 194 pages

Publisher's note Springer Nature remains neutral with regard to jurisdictional claims in published maps and institutional affiliations. 